DE ECONOMIST 156, NO. 3, 2008

\title{
ADOPTION SUBSIDY VERSUS TECHNOLOGY STANDARDS UNDER ASYMMETRIC INFORMATION
}

BY

\author{
IOULIA V. OSSOKINA*,*** AND OTTO H. SWANK**
}

\begin{abstract}
Summary
Market-based instruments are believed to create more efficient incentives for firms to adopt new technologies than command-and-control policies. We compare the effects of a direct technology regulation and of an adoption subsidy under asymmetric information about the costs of technological advances in controlling the socially undesirable activities. We show that the policy maker may want to commit to her policy. The reason is that asymmetric information about adoption costs induces the policy maker to set subsidy levels that increase over time; firms, expecting higher subsidies in the future, postpone investment. Direct regulation offers a commitment possibility that allows to prevent firms from postponing investment.
\end{abstract}

Key words: abatement technologies, asymmetric information, command-and-control instruments, market-based instruments

JEL Code(s): D80, H23, O38

\section{INTRODUCTION}

It is often argued that significant reductions in socially undesirable effects of economic activities can be achieved through a more widespread adoption of new technologies. The adoption of these technologies is frequently encouraged with regulatory policy. Let us discuss some examples. In order to limit the noise produced by motor vehicles, the European Commission has passed a directive that provides standards for tires and their fitting. To tackle polluting emissions, several countries have stimulated firms and households to purchase energy-efficient appliances and equipment. To this end both, subsidies (for example, the existing subsidy on the purchase of

* Corresponding author: CPB Netherlands Bureau for Economic Policy Analysis, P.O. Box 80510, 2508 GM The Hague, The Netherlands, e-mail: i.v.ossokina@cpb.nl

** Erasmus University Rotterdam and Tinbergen Institute, P.O. Box 1738, 3000 DR, Rotterdam, The Netherlands.

*** The research of the the first author was sponsored by the Netherlands Organization for Scientific Research NWO. We thank the participants of the First World Meeting of the Public Choice Society on March 29-April 1, 2007 in Amsterdam, and especially Frans van Winden, for comments. 
soot filters for diesel cars in the Netherlands) and direct regulation (e.g., the mandatory building energy codes that exist in most American states) have been used. To improve safety on the roads, the Dutch government encouraged road exploiters to introduce additional $30 \mathrm{~km}$ speed limit zones in the cities and towns and provided a subsidy to this end. With the same goal of road safety improvement, EU safety standards exist for bycicles and car seats for children. For the benefit of preventing health hazards, in the Netherlands house owners and tenants used to be subsidized to replace lead drinking water pipes, in the Dutch restaurants smoking is prohibited and there exist international ISO safety standards. ${ }^{1}$ Finally, in order to induce a certain quality level of desirable goods and services produced, many a country formulates requirements for production technology that is applied by a number of professions (among others, pharmacists, financial institutions, health centers, etc.). Meeting these requirements is in some cases mandatory (financial institutions worldwide usually have to fullfil strict requirements to get an operating licence); in other cases it is stimulated fiscally (e.g., in the Netherlands, general practitioners were subsidized to switch to electronic patient files).

It happens frequently that economic agents whose activity results in a socially undesirable effect, are relatively small and numerous. As the above examples suggest, when confronted with the necessity to regulate such agents, policy makers often choose between the direct regulation instrument and the market-based instrument subsidy on technology adoption. ${ }^{2}$ Many economists believe that market-based instruments of regulatory policy create more efficient incentives to adopt new technologies than command-and-control instruments. Perhaps the most important reason is that the latter tend to force regulated agents to take on similar shares of controlling for undesirable effects, regardless of the cost. Policy makers, however, often give preference to direct regulation. In this paper we show that in a world in which the regulated agents have private information on the costs of technological advances in controlling for undesirable effects, ${ }^{3}$ a policy maker may want to commit to her policy. Command-and-control instruments offer this

1 Standard 3691, for example, specifies the safety requirements for the manufacture, application, operation and maintenance of powered industrial trucks.

2 When the regulated agents are small and numerous, the otherwise widely used tax instrument has an important disadvantage in terms of the relative difficulty of the monitoring job it implies. Under the subsidy, monitoring is relatively easier as the instrument puts the burden of proof on the regulated agents. These agents must show that they use the 'right' technology to claim the award (Russell and Powell (1999)). It is thus no coincidence that in the above examples, regulatory policy mostly involves either a direct regulation or a subsidy.

3 This assumption is frequently seen as reasonable in the literature: see, e.g., Cadot and Sinclair-Desgagné (1996). 
commitment possibility and thus may have an important advantage over market-based instruments.

We develop a model for comparing policy outcomes under a direct technology regulation on the one hand and under an adoption subsidy on the other hand. The model revolves around a policy maker who cares about reducing the undesirable effects of an economic activity, the financial position of the government ${ }^{4}$ and the financial position of firms. ${ }^{5}$ Reducing the undesirable effects requires that firms adopt a new technology. The policy maker can compel firms to adopt the new technology or she can encourage the adoption of the new technology by subsidizing it. Three features of our model are worth mentioning. First, firms differ in the adoption costs. ${ }^{6}$ Second, our model is a model of asymmetric information: the policy maker does not observe the adoption cost of specific firms. Finally, our model is dynamic. The implication of the second feature is that in case of direct regulation, the policy maker cannot exempt firms with high adoption costs from regulation, while in case of a subsidy, the policy maker cannot offer firmspecific subsidies. The implication of the third feature, is that firms do not only have to make a decision whether or not to invest, but also have to decide when to invest.

We show that with forward-looking firms, the policy maker may want to commit herself. The reason is that when firms expect higher subsidies in the future, they will postpone investment. The reason why firms may expect higher subsidies in the future is that asymmetric information about firms' adoption costs induces the policy maker to set subsidy levels that increase over time. Basically, the policy maker can prevent firms from postponing investment in two ways. First, she can choose a sub-optimal high subsidy level in the first period. Second, she can compel firms to invest.

Our paper contributes to a small but interesting literature that provides explanations for the discrepancy between economists' recommendations and policy makers' actions concerning the choice of policy instrument. One stream in this literature focuses on the role of political factors in the decisionmaking process. For instance, the seminal paper of Buchanan and Tullock (1975) suggests that direct regulation is preferred over taxation by the regulated industry, which may be a politically influential interest group. The reason is that direct regulation assigns production quota's to existing firms and thus may have similar effects to cartel formation, leading to above-

4 As a rule, subsidies are financed with distortionary taxes. The cost of raising $\$ 1$ public funds to finance the subsidy amounts thus to $\$(1+\lambda)>\$ 1$ (Laffont and Tirole 1993, p. 24). 5 In Biglaiser et al. (1995) who analyze different policy instruments used in the land set-aside programs, the policy maker is influenced by similar concerns.

6 Potential adopters being characterized by a distribution of returns associated with the new technology is a usual assumption in the probit or rank models of technology diffusion (Jaffe et al. 2002, p. 47). 
normal profits. ${ }^{7}$ Glazer and Lave (1996) argue that a government facing a possibility to lose office to a less environment-concerned competitor may opt for direct regulation that ensures immediate environmental investment as opposite to market-based instruments under which firms can postpone investment. In this paper we analyze how the weights the policy maker puts on different policy goals influence her instrument choice.

Another stream in the literature that tries to explain the disagreement between economists and policy makers looks for possible flaws of marketbased instruments. Thus, Buchanan (1969) points out that when product markets are imperfect, a tax leads not only to a reduction in undesirable activities, but also to further production cuts and increased product prices. Stavins (1995) argues that the performance of tradeable permits can be adversely affected by transaction costs. ${ }^{8}$ Biglaiser et al. (1995) and Gersbach and Glazer (1999) show that in a dynamic setting tradeable permits and taxes may create incentives for firms to underinvest in technologies that control for undesirable activities, in order to restrict possibilities for strengthening the policy in the future. ${ }^{9}$ Saracho and Usategui (1994) suggest that an adoption subsidy, of which the level increases over time, may decrease social welfare and may reduce adoption speed as potential adopters postpone adoption to benefit from a higher subsidy. ${ }^{10}$ The studies pointing out flaws of marketbased instruments, have, however, paid little attention to a formal comparison of direct regulation and market-based instruments. ${ }^{11}$

Finally, our paper is connected to the studies on the effects of uncertainty on policy instrument choice. A seminal contribution by Weitzman (1974) points out that when the function of social benefits of pollution reduction is sharply curved, i.e. there is a high degree of risk aversion, quantity instruments are preferred to price instruments under uncertainty about costs of

7 See Hahn (1990, pp. 22-25) and Dijkstra (1999) for overviews of later studies on the influence of interest groups on the instrument choice.

8 Hahn (1984) studies the implications of imperfect product markets for tradeable emission permits. For a summary of literature analyzing factors negatively affecting the performance of permits see Stavins (1995).

9 Yao (1988) and Malik (1991) demonstrated, however, that similar effects may occur under direct regulation if its tightness can be adjusted over time.

10 Saracho and Usategui do not however analyse whether the policy maker has an incentive to set such a subsidy; we do this in this paper.

11 Two exceptions are Heyes (2001) and Sartzetakis (1997). Sartzetakis (1997) argues that under incomplete information the negative production effect of marketable emission permits in oligopolistic product markets is not large enough to mitigate the efficiency advantage of permits over direct regulation. Heyes (2001) shows that when part but not all of the regulated agents is underreporting their undesirable activities, an optimal tax will have a welfare cost of giving incorrect marginal abatement incentives to the firms; this cost may under some conditions result in the superiority of direct regulation. 
pollution control. The reason is that quantity instruments allow for rigid controllability of the environmental quality achieved (albeit at the price of uncertainty about the cost of achieving this quality). ${ }^{12}$

This paper is organized as follows. The next section presents a static model of instrument choice in which the policy maker knows the industry average adoption costs of the new technology, but does not observe the adoption costs of specific firms. In line with the literature we find that the subsidy allows the policy maker to screen out firms with high abatement costs, while direct regulation does not. Direct regulation, however, yields savings on public expenditures. In section 3, we show that in a dynamic model, the policy maker may have an incentive to set a lower subsidy-level in the first period than in the second period. The idea is that by dividing the market into firms with low and high adoption costs the policy maker can reduce total spending on subsidies. Of course, when firms anticipate that the subsidy level is higher in the second period, they will postpone investment. The punch line of section 3 is that the policy maker may want to commit herself to a stringent regulatory policy. Direct regulation can be interpreted as such a commitment. In sections 4 and 5 we analyse the influence of uncertainty about the average industry adoption costs on the policy instrument choice. Section 4 argues that in a static setting, uncertainty makes the subsidy instrument superior to the command-and-control instrument for a wider range of parameters. In section 5 we show that in a dynamic setting uncertainty and learning can be another reason for the policy maker to want to commit to stringent regulatory policy. Section 6 concludes.

\section{THE BASIC MODEL}

We consider an industry that consists of a continuum of firms. Initially, each firm owns a unit of an old technology, $T_{O}$. The use of $T_{O}$ leads to an undesirable activity $M$. The industry undesirable output under $T_{O}$ equal $M=M_{O}$. There exists a new technology, $T_{N}$. When a firm adopts $T_{N}$, its undesirable output is completely eliminated. Thus, if a fraction $\beta$ of the firms adopts the new technology, $M=(1-\beta) M_{O}$.

Each firm $i$ is characterized by an adoption cost parameter $c_{i}$. This parameter captures the cost of adopting $T_{N}$ for firm $i$. The $c_{i}$ 's are assumed to be uniformly distributed on the interval $\left[0, \frac{1}{\alpha}\right]$. For an individual firm, there are no benefits of adopting $T_{N}$. The implication is that without government

12 There exist quite a few extensions and applications of Weitzman's analysis (see for references, e.g., Cropper and Oates (1992), Montero (2002). Montero (2002) argues, for example, that incomplete enforcement further increases the relative importance of quantity instruments under uncertainty. When the costs of pollution control prove to be higher than expected, some firms choose not to comply thus reducing the total costs of the instrument. 
TABLE 1 - THE EFFECTS OF INSTRUMENTS ON POLICY OUTCOMES IN THE BASIC MODEL

\begin{tabular}{lll}
\hline Outcome/instrument & Direct regulation (DR) & Subsidies (S) \\
\hline Undesirable output $(M)$ & 0 & $M_{0}(1-\alpha S)$ \\
Public expenditures $(G)$ & 0 & $\alpha S^{2}$ \\
Financial position industry $(F C)$ & $-\frac{1}{2 \alpha}$ & $\frac{1}{2} \alpha S^{2}$ \\
\hline
\end{tabular}

intervention no firm adopts $T_{N}$ : firms must be motivated to adopt the new technology.

A policy maker is responsible for the design and implementation of policy that reduces $M$. In our model, the policy maker can choose between two instruments. First, the policy maker can compel firms to adopt $T_{N}$. We refer to this option as direct regulation (DR). Under direct regulation, all firms adopt $T_{N}$. We abstract from monitoring and enforcement costs and limit attention to two consequences of direct regulation: the undesirable output is eliminated, $M_{D R}=0$, and firms fully bear the cost of the adoption of $T_{N}$. Direct regulation thus affects the financial position of firms. The effect of DR on the financial position of the entire industry is: $F C_{D R}=-\int_{0}^{\frac{1}{\alpha}} \alpha i d i=-\frac{1}{2 \alpha}$. Second, the policy maker can subsidize the new technology. We assume that the policy maker knows the distribution of the $c_{i}$ 's, but does not observe the adoption cost of specific firms. As a consequence, the policy maker cannot offer firm-specific subsidies. The policy maker can thus choose a subsidy $S$, and firms decide whether or not to adopt $T_{N}$. In our model, subsidizing the new technology has three consequences. It reduces undesirable output of the industry. Assuming that all firms for which $c_{i} \leq S$ adopt $T_{N}$, we obtain that $M_{S}=\int_{S}^{\frac{1}{\alpha}} M_{0} \alpha d i=M_{0}(1-\alpha S) .{ }^{13}$ Moreover subsidizing $T_{N}$ leads to public expenditures, $G_{S}=\alpha S^{2}$. Finally, subsidizing $T_{N}$ affects the financial position of the industry, $F C_{S}$. Industry expenditures on $T_{N}$ are $\int_{0}^{S} \alpha i d i=\frac{1}{2} \alpha S^{2}$, while industry receipts are $\alpha S^{2}$. This implies that $F C_{S}=\frac{1}{2} \alpha S^{2}$. Table 1 summarizes the consequences of the choice of policy instrument for policy outcomes.

Basically, Table 1 shows that the choice between direct regulation and subsidies affects undesirable output and has distributional consequences. The policy maker is concerned with the undesirable output and with the distributional consequences of regulatory policy. Her preferences are described by the following quadratic-linear utility function:

$$
U=-\lambda_{1} M^{2}-\lambda_{2} G+F C, \quad \text { with } \lambda_{1}>0 \text { and } \lambda_{2}>1
$$

13 We assume that firms which expect not to loose from adopting $T_{N}$ adopt $T_{N}$. Until section 4, this assumtpion implies that firms for which $c_{i} \leq S$ adopt $T_{N}$. 
In equation (1), $\lambda_{1}$ denotes the weight the policy maker attributes to the undesirable output target relative to the distributional issue. One interpretation of parameter $\lambda_{2}$ is that it captures who, according to the policy maker, should bear the costs of regulatory policy. Under this interpretation, the assumption that $\lambda_{2}>1$ implies that the policy maker finds the financial position of the government more important than the financial position of the industry. An alternative interpretation of $\lambda_{2}$ is that costs are attached to collecting taxes required to finance public expenditures We realize that the specification of the utility function is somewhat ad hoc. However, we believe that (1) fits reasonable well with political discussions about regulatory policy. Those discussions often revolve around effectiveness, the consequences of the policy for the budget and the consequences for the competitiveness of industry. We employ a quadratic-linear utility function for mathematical tractability. This form is particularly useful when we introduce instrument uncertainty into the model (Brainard 1967).

In the next sections we augment the basic model by (a) introducing dynamics into the model and (b) adding uncertainty about the cost of the new technology, $\alpha$. Throughout, the model is used to identify the conditions under which direct regulation delivers a higher utility for the policy maker than subsidies.

We are aware that our model is rudimentary. We abstract from numerous important aspects of regulatory policy that are relevant for the evaluation of policy instruments. For example, it is well-known that subsidies may encourage undesirable activities, whereas direct regulation may discourage these activities. We ignore this aspect by assuming that the choice of instrument does not influence production decisions (neither at the firm level nor at the industry level). The advantage of our simple model is that it enables us to focus on the implications of asymmetric information and uncertainty for the evaluation of alternative policy instruments.

\subsection{Optimal Choice of Policy Instrument in the Basic Model}

We evaluate DR and S on the basis of equation (1). Using (1) and the outcomes under DR (presented in the first column of Table 1), it immediately follows that the policy maker's utility equals:

$$
U_{D R}=-\frac{1}{2 \alpha}
$$

Now suppose that $\mathrm{S}$ is the instrument. The optimal value of $S$ results from maximizing (1) with respect to $S$, given the outcomes presented in the second column of Table 1 . This yields: 


$$
S=\frac{\lambda_{1} M_{O}^{2}}{\alpha \lambda_{1} M_{O}^{2}+\lambda_{2}-\frac{1}{2}}
$$

Equation (3) shows that $S$ increases with $\lambda_{1}$ and $M_{O}$, and decreases with $\alpha$ and $\lambda_{2}$. Substitution of (3) into (1) gives policy maker's utility under S:

$$
U_{S}=-\frac{\lambda_{1} M_{O}^{2}\left(\lambda_{2}-\frac{1}{2}\right)}{\alpha \lambda_{1} M_{O}^{2}+\lambda_{2}-\frac{1}{2}}
$$

Using (2) and (4), it is easy to show that $\mathrm{S}$ is given preference over DR if

$$
\alpha<\alpha^{I}=\frac{\lambda_{2}-\frac{1}{2}}{2 \lambda_{1} M_{O}^{2}\left(\lambda_{2}-1\right)}
$$

where $\alpha^{I}$ denotes the value of $\alpha$ for which the policy maker is indifferent between $\mathrm{S}$ and DR. From the analysis the following three results emerge. First, if $\lambda_{2} \leq 1$ (contrary to what we have assumed), then $\mathrm{S}$ is always superior to DR. Second, if $\lambda_{2}>1$ (as assumed), then the policy maker prefers $S$ to DR when the industry average adoption costs are high (low $\alpha$ ). Third, the attractiveness of DR increases with $\lambda_{1}$ and $M_{O}$. To understand these results first note that DR leads to a "corner solution": no undesirable output and firms bear the total costs of $T_{N}$. In our model, $S$ is a more flexible instrument. It allows for the possibility that firms with high adoption costs do not adopt the new technology. Because the marginal benefits of reducing undesirable output go to zero if $S$ goes to $\frac{1}{\alpha}$, flexibility is an attractive property of an instrument. ${ }^{14}$ To put it differently, if the policy maker could observe the $c_{i}$ 's, then under DR she would exempt high cost firms from the obligation to adopt $T_{N}$. Clearly, the more the policy maker cares about reducing the undesirable output (higher $\lambda_{1}$ ), the less the policy maker values flexibility. The advantage of DR is that it does not involve costly redistribution from the government to the industry.

\section{DYNAMIC SETTING}

So far we have analyzed which factors influence the instrument choice when the policy decision is made once and for all. Now we will examine how the introduction of dynamics into the model affects the choice of the policy instrument. For notational simplicity we abstract from discounting.

We split our model into two parts. In period 1, with length of time $Z<1$, the policy maker chooses the policy instrument. In period 2, with

14 This is not the case if at $M_{O} \rightarrow 0$, the marginal benefit of reducing emissions is higher than $\frac{1}{\alpha}$. 
length of time $1-Z$, she can adjust the policy chosen. We make two alternating assumptions concerning the behavior of the firms. First, we assume that firms are naive, i.e. in every period firm $i$ maximizes its profit in that period. Second, we assume that firms are forward-looking: when taking the investment decision, firm $i$ maximizes its total profit over two periods.

It is easy to verify that if the policy maker chooses DR, introducing dynamics has no important implications. The reason is that under DR emissions are completely eliminated in period 1 and no government intervention is needed in period 2 . The remaining part of this section analyzes how dynamics affects the adoption subsidy.

\subsection{Naive Firms}

Let $S_{1}\left(S_{1} \geq 0\right)$ denote the subsidy level in period 1 and let $S_{2}\left(S_{2} \geq S_{1}\right)$ denote the subsidy level in period 2 . In line with the previous section we assume that (1) in period 1 all firms for which $c_{i} \leq S_{1}$ adopt $T_{N}$, and (2) in period 2 all firms for which $S_{1}<c_{i} \leq S_{2}$ adopt $T_{N}$. By setting $S_{2}>S_{1}$ the policy maker may differentiate the subsidy level between firms with high and low adoption costs. In such a way extra undesirable output can be avoided with relatively low expenditures in period $2 .{ }^{15}$ By choosing $S_{2}>S_{1}$ the policy maker postpones part of the reduction in undesirable output in order to gain a cut in the government expenditures.

Consider the dynamic version of the model of section 2. It is easy to verify that in our two-period model policy outcomes are:

$$
\begin{aligned}
M_{1} & =M_{0}\left(1-\alpha S_{1}\right) \\
G_{1} & =\alpha S_{1}^{2} \\
F C_{1} & =\frac{1}{2} \alpha S_{1}^{2}
\end{aligned}
$$

in period 1 , and

$$
\begin{aligned}
M_{2} & =M_{0}\left(1-\alpha S_{2}\right) \\
G_{2} & =\alpha S_{2}\left(S_{2}-S_{1}\right) \\
F C_{2} & =-\frac{1}{2} \alpha S_{2}^{2}+\frac{1}{2} \alpha S_{1}^{2}+\alpha S_{2}\left(S_{2}-S_{1}\right)
\end{aligned}
$$

in period 2. Using the above expressions we can write the dynamic version of the policy maker's utility function (1) as:

15 The reason for savings in expenditures is that the high subsidy of period 2 is not spent on firms with low adoption costs. Note that the existence of these savings hinges on the assumption $\lambda_{2}>1$. 


$$
\begin{aligned}
& -Z \lambda_{1} M_{0}^{2}\left(1-\alpha S_{1}\right)^{2}-(1-Z) \lambda_{1} M_{0}^{2}\left(1-\alpha S_{2}\right)^{2}-\lambda_{2}\left[\alpha S_{1}^{2}+\alpha S_{2}\left(S_{2}-S_{1}\right)\right] \\
& -\frac{1}{2} \alpha S_{2}^{2}+\alpha S_{1}^{2}+\alpha S_{2}\left(S_{2}-S_{1}\right)
\end{aligned}
$$

Differentiating (6) with respect to $S_{2}$ and solving the first-order condition yields:

$$
S_{2}^{*}=\frac{2(1-Z) \lambda_{1} M_{0}^{2}+\left(\lambda_{2}-1\right) S_{1}}{2(1-Z) \alpha \lambda_{1} M_{0}^{2}+2 \lambda_{2}-1}
$$

The cut-off value of $S_{1}$ implying $S_{2}^{*}=S_{1}$ equals:

$$
S_{1}^{S}=\frac{2(1-Z) \lambda_{1} M_{O}^{2}}{2(1-Z) \alpha \lambda_{1} M_{O}^{2}+\lambda_{2}}
$$

$S_{1}<S_{1}^{S}$ is a necessary condition for the policy maker to set $S_{2}>S_{1}$. From (8) it is easy to derive that $S_{1}^{S}$ decreases with $Z$. The shorter period 2 (the larger $Z$ ), the less utility the policy maker gets from extra decrease in undesirable output in that period and the less she is inclined to set $S_{2}>S_{1}$.

Lemma 3.1 If $Z \geq \frac{1}{2}$, then $S_{2}=S_{1}$.

Proofs of this and other results are in the Appendix.

Lemma 3.1 states that the policy maker will never differentiate the subsidy between firms with high and low costs if the low undesirable output of period 2 cannot be produced for a longer time than the higher undesirable output of period 1.

Proposition 3.1 Suppose $Z<\frac{1}{2}$. Then $S_{2}>S_{1}$ if and only if $\lambda_{2}>\frac{1-Z}{1-2 Z}$.

Proposition 3.1 indicates that if period 2 is longer than period 1 and the shadow cost of public funds, $\lambda_{2}$, is sufficiently large, the policy maker chooses a higher level of subsidy in period 2 than in period 1. To understand why for small values of $\lambda_{2} S_{2}=S_{1}$, note that when $\lambda_{2}=1$, subsidy differentiation is never optimal. The reason is that postponing part of the reduction in undesirable output yields no reductions in total expenditures. To make postponing attractive, $\lambda_{2}$ has to be sufficiently large.

\subsection{Forward-Looking Firms}

Above we have shown that if (1) firms are naive, (2) period 1 is shorter than period 2 and (3) the shadow cost of public funds is sufficiently large, then the policy maker differentiates the subsidy between firms with high and low adoption costs. An advantage of subsidies in a dynamic setting seems that the policy maker is able to mitigate the negative implications of the shadow 
TABLE 2 - THE STRUCTURE OF THE GAME BETWEEN THE POLICY MAKER AND THE FIRMS

Period 1

(1) The policy maker chooses the subsidy value: $S_{1} \in\left[0, \frac{1}{\alpha}\right]$.

(2) Firms observe $S_{1}$, each firm decides whether or not to invest.

\section{Period 2}

(3) The policy maker chooses whether or not to adjust the subsidy: $S_{2} \in\left[S_{1}, \frac{1}{\alpha}\right]$.

(4) Firms observe $S_{2}$, each firm using $T_{0}$ decides whether or not to invest.

cost of public funds. In this section, we show that appearances can be misleading. If firms are forward-looking, then the opportunity to differentiate the subsidy may lead to postponement of policy or to a too high level of subsidy.

We assume that the policy maker wants to differentiate the subsidy, i.e. $\lambda_{2}>\frac{1-Z}{1-2 Z}>0$. The stages of the game are described in Table 2.

To solve the game we will look for subgame-perfect Nash equilibria. To facilitate the exposition of the results we first introduce some notation. Let $q$ denote the adoption cost of the firm that is indifferent between investing and not investing in $T_{N}$ in period 1. Furthermore, let $\beta_{t}$ denote the share of firms investing in period $t$. Without loss of generality we assume that when the policy maker is indifferent between alternative values of $S_{1}$, she chooses the lowest of them; when firm $i$ is indifferent between investing in period 1 or in period 2, firm $i$ invests in period 1 .

To ensure a time-consistent solution, we first analyze behavior in period 2. Lemma 3.2 and Lemma 3.3 describe the optimal actions of firms and the optimal action of the policy maker, respectively.

Lemma 3.2 A firm invests in period 2 if $c_{i}>q$ and $c_{i} \leq S_{2}$; otherwise a firm does not invest in period 2.

Lemma 3.3 If $q<\frac{2(1-Z) \lambda_{1} M_{O}^{2}}{2(1-Z) \alpha \lambda_{1} M_{O}^{2}+\lambda_{2}}$, then $S_{2}=\frac{2(1-Z) \lambda_{1} M_{O}^{2}+\left(\lambda_{2}-1\right) q}{2(1-Z) \alpha \lambda_{1} M_{O}^{2}+2 \lambda_{2}-1}$; otherwise $S_{2}=S_{1}$.

Lemma 3.2 gives the decision rule of a firm: invest if the subsidy exceeds the cost; otherwise do not invest. Basically, this decision rule is similar to that of the static model. Lemma 3.3 shows that the optimal level of subsidy depends on the share of firms that has invested in period 1. If this share is small, then the policy rule is similar to that of the static model. If it is large, then $S_{2}=S_{1}$.

Now that we have derived the players' optimal actions in period 2, let us analyze what can happen in period 1. First consider firm behavior. Firms anticipate policy in period 2. Clearly, if $S_{2}>S_{1}$, no firm has an incentive to 
invest in period 1. Provided a firm invests, it will invest in that period in which the subsidy offered is highest. Lemma 3.4 directly follows from this result.

Lemma 3.4 If one or more firms invest in period $1\left(\beta_{1}>0\right)$, no firm will invest in period 2. If one or more firms will invest in period $2\left(\beta_{2}>0\right)$, no firm invests in period 1 .

We are now ready to identify the equilibria of the game.

Proposition 3.2 The game between the policy maker and the firms has two equilibria.

(I) the policy maker sets $S_{1}=0$ and $S_{2}^{*}=\frac{2(1-Z) \lambda_{1} M_{O}^{2}}{2(1-Z) \alpha \lambda_{1} M_{O}^{2}+2 \lambda_{2}-1}$; no firm invests in period 1, firms for which $c_{i} \leq S_{2}$ invest in period 2 .

(II) the policy maker sets $S_{1}=\frac{2(1-Z) \lambda_{1} M_{O}^{2}}{2(1-Z) \lambda_{1} M_{O}^{2} \alpha+\lambda_{2}}$ and $S_{2}=S_{1}$; firms for which $c_{i} \leq S_{1}$ invest in period 1 and no firm invests in period 2 .

Let us compare the two equilibria of the game described in Proposition 3.2. In the first equilibrium the policy maker postpones regulatory policy to period 2. In comparison with the static model the level of subsidy is low. The reason is that postponement reduces the benefits of the subsidy. Hence, a potential cost of the opportunity to differentiate the subsidy is undesirable output in period 1 . In the second equilibrium, the opportunity to differentiate the policy leads to a high level of subsidy in period 1 ( $S_{1}$ in equilibrium II is higher than $S$ in the static model without uncertainty about $\alpha$ ). The level of subsidy is too high in the sense that if the policy maker were able to commit herself to a lower subsidy, she would do so. The reason that the level of subsidy is high is that a lower level would induce the policy maker to set $S_{2}>S_{1}$. From the above discussion we know that $S_{2}>S_{1}$ means that no firm will invest in period 1. To prevent firms from postponing to invest, the policy maker chooses a high level of subsidy.

Let us now elaborate upon the conditions under which each of the equilibria can occur. First, it is worth noting that in our game the policy maker is the first-mover. By choosing $S_{1}$, she can select "the equilibrium of the game". More precisely, which equilibrium occurs depends on which of the equilibria is optimal from the policy maker's point of view. Above we have already discussed the pros and cons of the equilibria. We know that if the policy maker assigns high priority to fighting the undesirable output, she is ready to incur higher costs to achieve a reduction in it. Therefore, if the government cares much about reducing the undesirable output, the second equilibrium is likely to occur. The policy maker can avoid a high level of subsidy by postponing policy. The cost is undesirable output in period 1. Thus, the first equilibrium is likely to occur if the policy maker does not care much about the 
undesirable output and faces a large shadow cost of public funds, or if the length of period $1, Z$, is small.

In the above setting the flexibility of the subsidy instrument may lead to strategic behaviour with negative welfare implications when the first period is shorter than the second period. ${ }^{16}$ In the next sections we analyse another case when the policy maker may want to increase the subsidy level strategically, namely uncertainty about the adoption costs of the industry.

\section{THE EFFECT OF UNCERTAINTY ABOUT ADOPTION COSTS ON THE CHOICE OF INSTRUMENT}

In this section we introduce uncertainty about adoption costs of the new technology into the static model of section 2. In the next section the effects of uncertainty in a dynamic model will be analysed. In the augmented model, the parameter $\alpha$ can take the value $\bar{\alpha}+h$ or take the value $\bar{\alpha}-h$, with $h<\bar{\alpha}$. Each possibility occurs with probability 0.5 . Firms know $\alpha$, but the policy maker does not. We ask ourselves how does uncertainty about $\alpha$ affect the choice of policy instrument.

Suppose that the policy maker chooses DR. As in section 2, DR implies that undesirable output is eliminated and that firms fully bear the adoption costs of the new technology. Under DR, the policy maker's expected utility equals:

$$
E\left(U_{D R}\right)=-\frac{\bar{\alpha}}{2\left(\bar{\alpha}^{2}-h^{2}\right)}
$$

where $E$ is the expectation operator. The implication of uncertainty about $\alpha$ is that the financial position of the industry becomes uncertain. Equation (9) shows that an increase in $h$ decreases the policy maker's expected utility.

Now suppose $\mathrm{S}$ is the policy instrument. The policy maker's expected utility as a function of $S$ is:

$$
\begin{aligned}
E\left(U_{S}\right)= & \frac{1}{2}\left\{-\lambda_{1} M_{O}^{2}[1-(\bar{\alpha}-h) S]^{2}+\left(\frac{1}{2}-\lambda_{2}\right)(\bar{\alpha}-h) S^{2}\right\} \\
& +\frac{1}{2}\left\{-\lambda_{1} M_{O}^{2}[1-(\bar{\alpha}+h) S]^{2}+\left(\frac{1}{2}-\lambda_{2}\right)(\bar{\alpha}+h) S^{2}\right\} \\
= & -\lambda_{1} M_{O}^{2}\left[1-2 \bar{\alpha} S+\left(\bar{\alpha}^{2}+h^{2}\right) S^{2}\right]+\left(\frac{1}{2}-\lambda_{2}\right) \bar{\alpha} S^{2}
\end{aligned}
$$

Equation (10) shows that under $\mathrm{S}, h$ affects the policy maker's expected utility through the undesirable output objective. Thus, a difference between

16 As the amount of the subsidy offered is often being reconsidered in the beginning of a new year, $Z<\frac{1}{2}$ may be the case if the subsidy is introduced during the year. 
the two policy instruments is the way they allocate risk. Under S, risk is allocated to the undesirable output target, while under DR, the industry bears the risk. This difference implies that when the policy maker cares much about the undesirable output (high $\lambda_{1}$ ), she wants to allocate risk to firms rather than to the undesirable output. She can do so by choosing DR as policy instrument. ${ }^{17}$ More generally, the parameters $\lambda_{1}$ and $\lambda_{2}$ determine how the policy maker wants to allocate risk.

How does $S$ respond to uncertainty about $\alpha$ ? Maximizing (10) with respect to $\mathrm{S}$ yields:

$$
S^{*}=\frac{\lambda_{1} M_{O}^{2}}{\frac{\bar{\alpha}^{2}+h^{2}}{\bar{\alpha}} \lambda_{1} M_{O}^{2}+\lambda_{2}-\frac{1}{2}}
$$

From equation (11) is easy to see that $S^{*}$ decreases with $h$. This result is in line with Brainard (1967) who argues that uncertainty about policy effects should lead to a conservative use of instruments. Together (10) and (11) provide an argument for choosing subsidies as policy instrument rather than direct regulation. Subsidies can be adjusted. This property enables the policy maker to reduce the adverse consequences of uncertainty.

In summary, uncertainty about adoption costs affects instrument choice in two ways. First, different instruments allocate risk in different ways. How risk should be allocated depends on preferences. Second, the introduction of uncertainty enhances the importance of a flexible instrument.

\section{UNCERTAINTY ABOUT ADOPTION COSTS IN A DYNAMIC SETTING}

In this section we analyze how uncertainty about $\alpha$ affects the level of the subsidy in a two-period model. ${ }^{18}$ We assume that period 1 and 2 are of equal length. From section 3 we know that under this assumption the policy maker does not differentiate the subsidy between firms with high and low adoption costs. So, if the policy maker will set $S_{2}>S_{1}$ in the present model, then uncertainty about $\alpha$ is the cause.

As in section 3, we start the analysis by assuming that (1) in period 1 all firms for which $c_{i} \leq S_{1}$ adopt $T_{N}$, and (2) in period 2 all firms for which $S_{1}<c_{i} \leq S_{2}$, adopt $T_{N}$. Having explained the reason why the policy maker may want to choose $S_{2}>S_{1}$ when firms are naive, we proceed to analyze the case that firms are forward-looking.

17 We can show that this effect may cause that the policy maker prefers DR to $\mathrm{S}$ when $\lambda_{2}=1$. Recall that in the basic model, the policy maker always prefers $S$ to $D R$ when $\lambda_{2}=1$. 18 As the DR policy cannot be adjusted, its performance under uncertainty in a two-period model is the same as in the one-period model of section 4 . 


\subsection{Naive Firms}

As in section 4 , the parameter $\alpha$ can take the value $\bar{\alpha}+h$ or the value $\bar{\alpha}-h$ with equal probability. Since in period 1 firms for which $c_{i} \leq S_{1}$ adopt $T_{N}$, the policy maker learns the value of $\alpha$ if $S_{1}>0$. Then, in period 2 the policy maker makes her decision under certainty. Differentiating period 2 utility

$$
\begin{aligned}
& -\frac{1}{2} \lambda_{1} M_{0}^{2}\left(1-\alpha S_{2}\right)^{2}-\lambda_{2}\left[\alpha S_{2}\left(S_{2}-S_{1}\right)\right] \\
& -\frac{1}{2} \alpha S_{2}^{2}+\frac{1}{2} \alpha S_{1}^{2}+\alpha S_{2}\left(S_{2}-S_{1}\right)
\end{aligned}
$$

with respect to $S_{2}$ yields

$$
S_{2}^{*}=\frac{\lambda_{1} M_{0}^{2}+S_{1}\left(\lambda_{2}-1\right)}{\alpha \lambda_{1} M_{0}^{2}+2 \lambda_{2}-1}
$$

Clearly, $S_{2}>S_{1}$ requires

$$
S_{1}<\frac{\lambda_{1} M_{O}^{2}}{\alpha \lambda_{1} M_{O}^{2}+\lambda_{2}}
$$

Lemma 5.1 In equilibrium if the policy maker learns that $\alpha=\bar{\alpha}+h$ then $S_{2}=S_{1}$.

The reason for Lemma 5.1 is obvious. If $\alpha$ is known, then the optimal level of subsidy is decreasing in $\alpha$. Uncertainty about $\alpha$ implies that the policy maker runs the risk of choosing a wrong level. The policy maker, however, knows that the optimal level of subsidy is equal to (3) either with $\alpha=\bar{\alpha}+h$ or with $\alpha=\bar{\alpha}-h$. Hence, in period 1 the subsidy level chosen will be at least (3) with $\alpha=\bar{\alpha}+h$; from (13) and (14) it follows that $S_{2}^{*}=S_{1}$ if $\alpha=\bar{\alpha}+h$.

Proposition 5.1 gives the condition under which the policy maker chooses $S_{2}>S_{1}$ if she learns that $\alpha=\bar{\alpha}-h$.

Proposition 5.1 Let $h^{\prime}=\frac{1}{2}\left[\sqrt{\bar{\alpha}^{2}+\frac{2 \bar{\alpha}}{\lambda_{1} M_{O}^{2}}}-\bar{\alpha}\right]$. When $h>h^{\prime}$, then $S_{2}>S_{1}$ if the policy maker learns that $\alpha=\bar{\alpha}-h$. Otherwise $S_{2}=S_{1}$ if the policy maker learns that $\alpha=\bar{\alpha}-h$.

Proposition 5.1 shows that if uncertainty about $\alpha$ is sufficiently large, then the policy maker chooses a higher level of subsidy in period 2 than in period 1 when the costs of adoption of the new technology turn out to be large. Hence, in a dynamic setting a flexible instrument as subsidies seems to have the advantage of mitigating the adverse consequences of uncertainty. To 
understand why for small values of $h S_{2}=S_{1}$ even if $\alpha=\bar{\alpha}-h$, recall from section 3 that the policy maker does not want to set $S_{2}>S_{1}$ if the periods are of equal length. There is a bias against discrimination. To offset this bias, $h$ should be sufficiently large.

\subsection{Forward-Looking Firms}

Above we have shown that if (1) firms are naive, and (2) uncertainty about the effectiveness of subsidy is sufficiently large, then the policy maker bases policy in period 2 on past experiences. An advantage of subsidies over direct regulation seems that subsidies give an opportunity for learning. In this section, we show that if firms are forward-looking, an opportunity for learning appears to have negative implications. It may lead to postponement of policy or to a too high level of subsidy.

With forward-looking firms, we have a game of incomplete information. The stages of this game are presented in Table 3.

To solve the game, we look for Bayesian-Nash equilibria, in which players' strategies are optimal responses to each other, and beliefs are updated according to Bayes' rule.

To facilitate the exposition of the results let $\rho$ denote the posterior probability that $\alpha=\bar{\alpha}+h$, and $\widehat{\alpha}=\bar{\alpha}+\rho h-(1-\rho) h$. As in section 3, $q$ denotes the adoption cost of the firm that is indifferent between investing and not investing in $T_{N}$ in period 1 , and $\beta_{t}$ denotes the share of firms investing in period $t$. Consider first firm behavior. Since firms know $\alpha$, their actions in period 1 and period 2 follow the same rules as in section 3 and can be described by Lemma 3.2 and Lemma 3.4. Thus, a firm invests in period 2 if the subsidy exceeds its adoption cost and otherwise it does not invest. Furthermore, provided a firm invests, it will invest in that period in which the subsidy offered is highest. Let us now turn to the policy maker who in period 1 faces uncertainty

TABLE 3 - THE STRUCTURE OF THE GAME BETWEEN THE POLICY MAKER AND THE FIRMS

Period 1

(1) Nature draws $\alpha$ and reveals it to the firms but not to the policy maker.

(2) The policy maker chooses the subsidy value: $S_{1} \in\left[0, \frac{1}{\alpha-h}\right]$.

(3) Each firm observes the policy and decides whether or not to invest.

(4) The policy maker observes the behavior of firms and revises her belief about $\alpha$.

Period 2

(5) The policy maker chooses whether or not to adjust the subsidy: $\left(S_{2} \mid \alpha\right) \in\left[S_{1}, \frac{1}{\alpha}\right]$

(6) Each firm using $T_{0}$ observes the policy and decides whether or not to invest. 
about $\alpha$. Lemma 3.3 with $Z=\frac{1}{2}$ describes the action in period 2 of the policy maker who has learned the value of $\alpha$.

We are now ready to identify the possible equilibria of the game. As is usual in games with incomplete information, our game has pooling and separating equilibria. In the pooling equilibrium, the policy maker does not learn anything about $\alpha$, implying $\rho=\frac{1}{2}$. This requires that, irrespective of the value of $\alpha$, no firm invests in period $1 .^{19}$ Consequently, in a pooling equilibrium the optimal level of subsidy can be calculated in the same way as (11) in section $4 .^{20}$

Proposition 5.2 In a pooling equilibrium, the policy maker sets $S_{1}=0$ and $S_{2}^{*}=$ $\frac{\lambda_{1} M_{O}^{2}}{\frac{\alpha^{2}+h^{2}}{\bar{\alpha}} \lambda_{1} M_{O}^{2}+2 \lambda_{2}-1}$; no firm invests in period 1 , firms for which $c_{i} \leq S_{1}$ invest in period $2 ; \rho$, the posterior probability that $\alpha=\bar{\alpha}+h$, equals $\frac{1}{2}$.

The equilibrium described by proposition 5.2 is similar to equilibrium I of section 3.2. The policy maker postpones policy to period 2 and the optimal level of subsidy is low in comparison with the static model with uncertainty about $\alpha$.

In a separating equilibrium, the policy maker learns $\alpha$. Learning requires that in period 1 firm behavior depends on the realization of $\alpha$. From Lemma 3.4 , it directly follows that $S_{2}>S_{1}$ and $\beta_{1}>0$ if $\alpha=\bar{\alpha}-h$ (as in section 5.1) is not possible when firms are forward-looking. The reason is that when $\alpha=\bar{\alpha}-h$, firms anticipate a subsidy increase and postpone investment. Below we show that learning requires postponement of policy if $\alpha=\bar{\alpha}-h$. If the policy maker wants to ensure investment in period 1, she has to commit herself not to make use of the opportunity for learning; we show that she can do so by offering a too high level of subsidy.

Proposition 5.3 states that there are two separating equilibria. ${ }^{21}$

Proposition 5.3 There are two separating equilibria.

(I) the policy maker sets $S_{1}=\frac{\lambda_{1} M_{O}^{2}}{\lambda_{1} M_{O}^{2}(\bar{\alpha}-h)+\lambda_{2}}$ and $S_{2}=S_{1}$; firms for which $c_{i} \leq S_{1}$ invest in period 1 and no firm invests in period 2 ; if $\beta_{1}=(\bar{\alpha}+h) S_{1}$, then $\rho=1$; if $\beta_{1}=(\bar{\alpha}-h) S_{1}$, then $\rho=0$

19 To understand why suppose $q>0$. In a pooling equilibrium, $q$ must be independent of $\alpha$. Consequently, firm $q$ must be indifferent between investing and not investing both when $\alpha=\bar{\alpha}+h$ and when $\alpha=\bar{\alpha}-h$. As $c_{i}$ is continuous and $h>0$, this cannot occur.

20 Of course, out-of-equilibrium beliefs are important. In the pooling equilibrium, we assume that $\rho=\frac{1}{2}$, irrespective of $\beta_{1}$.

21 Several assumptions about out-of equilibrium beliefs can be made which support the equilibria presented in Proposition 5.3. 
(II) the policy maker sets $S_{1}=\frac{\lambda_{1} M_{O}^{2}}{\lambda_{1} M_{O}^{2}(\bar{\alpha}+h)+\lambda_{2}-\frac{1}{2}}$ in period 1 , and $S_{2}=S_{1}$ if $\beta_{1}=$ $(\bar{\alpha}+h) S_{1}$ and $S_{2}=\frac{\lambda_{1} M_{O}^{2}}{\lambda_{1} M_{O}^{2}(\bar{\alpha}-h)+2 \lambda_{2}-1}$ if $\beta_{1}=0$; if $\alpha=\bar{\alpha}+h$ firms for which $c_{i} \leq S_{1}$ invest in period 1 and no firm invests in period 2 ; if $\alpha=\bar{\alpha}-h$ firms for which $c_{i} \leq S_{2}$ invest in period 2 and no firm invests in period 1; if $\beta_{1}=$ $(\bar{\alpha}+h) S_{1}$, then $\rho=1$; if $\beta_{1}=0$, then $\rho=0$.

Propositions 5.2 and 5.3 imply that our game has three equilibria. Below we will show that which of them occurs depends on the parameters of the model. We first compare the equilibria. The main drawback of the pooling equilibrium is pollution in period 1. The first separating equilibrium is similar to equilibrium II of section 3.2. The level of subsidy is too high in the sense that if the policy maker were able to commit herself to a lower subsidy, she would do so. However, without the possibility to commit, a lower subsidy level would induce the policy maker to set $S_{2}>S_{1}$ if she would learn that $\alpha=\bar{\alpha}-h$; this would have the undesirable effect that firms postpone investment in the new technology as in the pooling equilibrium. In the second separating equilibrium, period- 2 policy depends on the outcomes in period 1 . The benefit is that the level of subsidy is optimal if $\alpha=\bar{\alpha}+h$, and that the level is adjusted when it turns out that $\alpha=\bar{\alpha}-h$. There is also a cost. If $\alpha=\bar{\alpha}-h$, then firms do not invest in period 1.

Let us now discuss the conditions under which each of the equilibria can occur. As the policy maker is the first-mover in our game, the equilibrium occurs that is optimal from the policy maker's point of view. Above we have already dealt with the pros and cons of the equilibria. We know that if the policy maker cares much about reducing the undesirable output, she (1) is ready to incur higher costs in order to achieve reduction of undesirable output; (2) allocates high cost to uncertainty about the amount of undesirable output (section 4). Therefore, if the government cares much about reducing the undesirable output, the first separating equilibrium is likely to occur. If, in addition, uncertainty about the industry average adoption cost is high, then the second separating equilibrium becomes attractive. When the policy maker does not care much about the undesirable output, she prefers to avoid the high subsidy of the first separating equilibrium, especially when the shadow cost of public funds is large. This can be done by postponing policy or by making use of the opportunity for learning. The cost of postponing policy is undesirable output in period 1 and uncertainty about the amount of it in both periods. Overall in a dynamic model the introduction of uncertainty about the costs of regulation reduces the attractiveness of the subsidy in comparison with direct regulation.

Proposition 5.4 gives the conditions under which each of the three equilibria occurs. 
Proposition 5.4 Let $h^{\prime \prime}=\frac{2 \lambda_{2}-1}{4 \lambda_{1} M_{0}^{2}}\left(h^{\prime \prime}>h^{\prime}\right.$, where $h^{\prime}$ is determined in Proposition 5.1.) Then

(i) The second separating equilibrium is feasible if and only if uncertainty is high enough $\left(h>h^{\prime \prime}\right)$.

(ii) If the opportunity for learning can be used $\left(h>h^{\prime \prime}\right)$, then the pooling equilibrium never occurs. In that case either the opportunity for learning is made use of (second separating equilibrium) or immediate certain reduction in undesirable output is achieved at the cost of a too high subsidy (first separating equilibrium).

(iii) If the opportunity for learning cannot be used $\left(h \leq h^{\prime \prime}\right)$, then either the policy is postponed (pooling equilibrium) or immediate certain reduction in undesirable output is achieved at the cost of a too high subsidy (first separating equilibrium).

(iv) The opportunity for learning is welfare improving if (1) uncertainty about the adoption cost is high relative to the expected value of the industry average adoption costs $\left(\frac{h}{\bar{\alpha}}>\frac{\sqrt{3}}{3}\right)$ and (2) the policy maker cares much about the undesirable output $\left(\lambda_{1} M_{O}^{2}\right.$ is large). In all other cases the opportunity for learning is welfare reducing.

(v) If conditions (1) and (2) of (iv) hold, then the second separating equilibrium takes place.

\section{CONCLUDING REMARKS}

Many economists believe that market-based instruments for regulating socially undesirable activities create more efficient incentives for firms to adopt new technologies than command-and-control policies. Policy makers, however, often prefer direct regulation. In this paper we have shown that under asymmetric information about the costs of technological advances in controlling for undesirable effects, a policy maker may want to commit to her policy. Command-and-control instruments offer this commitment possibility and thus may have an important advantage over market-based instruments.

We have developed a model for comparing the effects of a direct technology regulation on the one hand and the effects of adoption subsidy on the other hand. First, we have studied the case in which the policy decision is made once and for all. The results we have obtained are generally in line with the literature on market versus command-and-control instruments. We have found that the subsidy allows the policy maker to screen out firms with high abatement costs, while direct regulation does not. Direct regulation, however, yields savings on public expenditures. Under uncertainty about policy effects 
the flexible subsidy instrument gains in importance except for the case when the policy maker cares much about reducing the undesirable activity.

Next, we have introduced dynamics into the model. We have found that with forward-looking firms, the policy maker may want to commit herself. The reason is as follows. The policy maker may have an incentive to set a lower subsidy-level in the first period than in the second period. The idea is that by dividing the market into firms with low and high adoption costs the policy maker can reduce total spending on subsidies. Furthermore, under uncertainty about the effectiveness of the subsidy, a lower subsidy in the first period allows the policy maker to base her policy in the second period on past experiences. Of course, when forward-looking firms anticipate that the subsidy level is higher in the second period, they postpone investment. In our model the policy maker can prevent firms from postponing investment in two ways. First, she can choose a sub-optimal high subsidy level in the first period. Second, she can compel firms to invest using direct regulation. Direct regulation can be interpreted as a commitment.

Our analysis is based on several restrictive assumptions. Some of them are made for simplification; relaxing these assumptions does not affect our results qualitatively. For example, in the dynamic version of our model neither the policy maker nor the firms discount the future. It is easy to show that the introduction of discounting into our model does not qualitatively affect our results. Furthermore, we have neglected the fact that in reality usually several versions of one technology are available (for example, older and newer ones), different in price and the extent to which they reduce undesirable activity. Introducing this aspect into the model and allowing the policy maker to choose which technology version to compel the firms to, will increase the flexibility of direct regulation, but will not affect the commitment possibility it provides.

A less innocuous assumption is that regulation does not affect production decisions of the firms. Relaxing this assumption brings about the issue of the entry to/exit from the industry and the connected discussion about the effects of the instruments on the industry level, which we intentionally wanted to avoid.

Though our results are derived from a highly stylized model, we believe that they are important for two reasons. First, command-and-control instruments are generally disliked by the economists. We have pointed out situations, in which the much discussed disadvantages of direct regulation can turn into its advantages. Second, our analysis has positive implications. It shows how the preferences of the policy maker affect the instrument choice when there is asymmetric information about the costs of technological advances in controlling the socially undesirable effects. 


\section{APPENDIX}

\section{Proof of lemma 3.1}

Proof. The policy maker's utility function in the dynamic setting, $U^{d}$, consists of two parts. On $S_{1} \geq S_{1}^{S}$, where $S_{1}^{S}$ is given by (8), the utility function is described by (1) with the values of parameters taken from Table 1; on $S_{1}<S_{1}^{S}$ it is described by (6). Since both parts of $U^{d}$ are quadratic in $S_{1}$ and $\left.\frac{\partial U^{d}}{\partial S_{1}}\right|_{S_{1}^{s}}=\left.\frac{\partial U^{d}}{\partial S_{1}}\right|_{S_{1} \uparrow S_{1}^{s}}$, we can conclude that $U^{d}$ has only one maximum in $S_{1}$. Thus, if the static optimum subsidy value $S^{\text {stat }}$ as defined by (3) meets the condition $S^{\text {stat }} \geq S_{1}^{S}$, then $U^{d}$ reaches its maximum at $S^{\text {stat }}$. It is easy to check that $S^{\text {stat }} \geq S_{1}^{S}$ always holds if $Z \geq \frac{1}{2}$.

\section{Proof of proposition 3.1}

Proof. Suppose $Z<\frac{1}{2}$ and $S^{\text {stat }}$ as defined by (3). Then it can be checked that $S^{\text {stat }} \geq S_{1}^{S}$ iff $\lambda_{2} \leq \frac{1-Z}{1-2 Z}$. Consequently, if $\lambda_{2}>\frac{1-Z}{1-2 Z}$, then the maximum of $U^{d}$ lies in the interval $S_{1}<S_{1}^{s}$. We know that if $S_{1}<S_{1}^{s}$, then $S_{2}^{*}>S_{1}$.

\section{Proof of lemma 3.2}

Proof. The result of the lemma directly follows from the definition of $q$.

\section{Proof of lemma 3.3}

Proof. By assumption firms for which $c_{i} \leq q$ have invested in period 1. Then the period-2 utility of the policy maker equals

$$
\begin{aligned}
& -(1-Z) \lambda_{1} M_{0}^{2}\left(1-\alpha S_{2}\right)^{2}-\lambda_{2}\left[\alpha S_{2}\left(S_{2}-q\right)\right] \\
& -\frac{1}{2} \alpha S_{2}^{2}+\frac{1}{2} \alpha q^{2}+\alpha S_{2}\left(S_{2}-q\right)
\end{aligned}
$$

Differentiating the above expression with respect to $S_{2}$ and solving the firstorder condition yields $S_{2}^{*}=\frac{2(1-Z) \lambda_{1} M_{O}^{2}+\left(\lambda_{2}-1\right) q}{2(1-Z) \alpha \lambda_{1} M_{O}^{2}+2 \lambda_{2}-1}$. It is optimal for the policy maker to set $S_{2}=S_{2}^{*}$ if $S_{2}^{*}>q$ and to set $S_{2}=S_{1}$ otherwise. The inequality $S_{2}^{*}>q$ holds if $q<\frac{2(1-Z) \lambda_{1} M_{O}^{2}}{2(1-Z) \alpha \lambda_{1} M_{O}^{2}+\lambda_{2}}$.

\section{Proof of proposition 3.2}

Proof. In this proof we show for both equilibria that the strategies of the firms and the strategy of the policy maker are optimal responses to each 
other. Note that lemma 3.2 and lemma 3.3 describe the optimal behavior of the firms and the optimal behavior of the policy maker in period 2 .

\section{Equilibrium I.}

(a) The optimal response of firm $i$ to $S_{2}>S_{1}$ is never to invest in period 1 and to invest in period 2 if $c_{i} \leq S_{2}$. If all firms follow this strategy, no firm can be better off by deviating.

(b) As $q=0, S_{2}=\frac{2(1-Z) \lambda_{1} M_{O}^{2}}{2(1-Z) \alpha \lambda_{1} M_{O}^{2}+2 \lambda_{2}-1}$ (lemma 3.3). Furthermore, as no firm invests in period 1, it is weakly optimal for the policy maker to set $S_{1}=0$.

Equilibrium II.

(a) The optimal response of firm $i$ to $S_{2}=S_{1}$ is to invest in period 1 if $c_{i} \leq$ $S_{1}$ and never to invest in period 2. If all firms follow this strategy, no firm can be better off by deviating.

(b) In order for the strategy of firms to hold in equilibrium, $S_{2}=S_{1}$ must be true. This implies that $S_{1} \geq S_{1}^{s}$, where $S_{1}^{s}$ is given by (8). It is easy to show that given this constraint, the policy maker maximizes her utility in period 1 by setting $S_{1}=S_{1}^{S}=\frac{2(1-Z) \lambda_{1} M_{0}^{2}}{2(1-Z) \alpha \lambda_{1} M_{0}^{2}+\lambda_{2}}$.

\section{Proof of proposition 5.1}

Proof. The policy maker's expected utility function in the dynamic setting under uncertain $\alpha, E U^{d u}$, consists of two parts: where (14) with $\alpha=\bar{\alpha}-h$ does not hold, it is described by (10), and where (14) with $\alpha=\bar{\alpha}-h$ holds, it is described by:

$$
\begin{aligned}
& \frac{1}{2}\left\{-\lambda_{1} M_{O}^{2}\left[1-(\bar{\alpha}+h) S_{1}\right]^{2}+\left(\frac{1}{2}-\lambda_{2}\right)(\bar{\alpha}+h) S_{1}^{2}\right\} \\
& \quad+\frac{1}{2}\left\{-\frac{1}{2} \lambda_{1} M_{0}^{2}\left(1-(\bar{\alpha}-h) S_{1}\right)^{2}-\frac{1}{2} \lambda_{1} M_{0}^{2}\left(1-(\bar{\alpha}-h) S_{2}\right)^{2}\right. \\
& \quad-\lambda_{2}\left[(\bar{\alpha}-h) S_{1}^{2}+(\bar{\alpha}-h)\left(S_{2}-S_{1}\right) S_{2}\right] \\
& \left.\quad-\frac{1}{2}(\bar{\alpha}-h) S_{2}^{2}+(\bar{\alpha}-h) S_{1}^{2}+(\bar{\alpha}-h)\left(S_{2}-S_{1}\right) S_{2}\right\}
\end{aligned}
$$

where $S_{2}$ is defined by (13) with $\alpha=\bar{\alpha}-h$.

Since both parts of $E U^{d u}$ are quadratic in $S_{1}$ and $\frac{\partial E U^{d u}}{\partial S_{1}}$ is everywhere continuous, the function has only one maximum in $S_{1}$. If the static optimum under uncertain $\alpha$ (11) does not meet condition (14) with $\alpha=$ $\bar{\alpha}-h$, then $E U^{d u}$ reaches its maximum at (11). Otherwise, in the optimum $S_{1}<S_{2}$, where $S_{2}$ is defined by (13) with $\alpha=\bar{\alpha}-h$. It is easy to show that for 
$h \geq 0$ (11) meets (14) with $\alpha=\bar{\alpha}-h$ iff $h>h^{\prime}=\frac{-\lambda_{1} M_{O}^{2} \bar{\alpha}+\sqrt{\left(\lambda_{1} M_{O}^{2} \bar{\alpha}\right)^{2}+2 \lambda_{1} M_{O}^{2} \bar{\alpha}}}{2 \lambda_{1} M_{O}^{2}}=$ $\frac{1}{2}\left[\sqrt{\bar{\alpha}^{2}+\frac{2 \bar{\alpha}}{\lambda_{1} M_{O}^{2}}}-\bar{\alpha}\right]$.

\section{Proof of proposition 5.2}

Proof. In this proof we proceed along the following steps: (a) we show that $\rho$ follows from Bayes' rule given the strategies of the firms; (b) we show that the strategy of firm $i$ is an optimal response to the strategy of the policy maker and the strategies of other firms; (c) we show that the strategy of the policy maker is an optimal response to the strategies of the firms given $\rho$. Note that the pooling equilibrium requires $q=0$ (see footnote 19).

(a) Since no firm invests in period 1, the policy maker does not learn anything about $\alpha$, and $\rho=\frac{1}{2}$.

(b) The optimal response of firm $i$ to $S_{2}>S_{1}$ is never to invest in period 1 and to invest in period 2 if $c_{i} \leq S_{2}$. If all firms follow this strategy, no firm can be better off by deviating.

(c) As $\beta_{1}=0$, we can obtain $S_{2}=\frac{\lambda_{1} M_{O}^{2}}{\frac{\bar{\alpha}^{2}+h^{2}}{\bar{\alpha}} \lambda_{1} M_{O}^{2}+2 \lambda_{2}-1}$ analogously to the derivation of the optimal subsidy value in section 4 . Furthermore, as no firm invests in period 1, it is weakly optimal for the policy maker to set $S_{1}=0$.

\section{Proof of proposition 5.3}

Proof. In this proof for every equilibrium we follow the same steps as in proposition 5.2. Recall from the main text that lemma 3.2 and lemma 3.3 with $Z=\frac{1}{2}$ describe the optimal behavior of the firms and the optimal behavior of the policy maker in period 2 .

1. First separating equilibrium

(a) If firms, for which $c_{i} \leq S_{1}$, invest in period 1 , then $\beta_{1}=\alpha S_{1}$ is dependent on $\alpha$. Consequently, the policy maker adjusts her belief in period 2 to $\rho=1$ if $\beta_{1}=(\bar{\alpha}+h) S_{1}$ and to $\rho=0$ if $\beta_{1}=(\bar{\alpha}-h) S_{1}$.

(b) The best response of firm $i$ to $S_{2}=S_{1}$ is to invest in period 1 if $c_{i} \leq S_{1}$ and never to invest in period 2. If all firms follow this strategy, no firm can be better off by deviating.

(c) In order for the strategy of firms to hold in equilibrium, $S_{2}=S_{1}$ must be true for any value of $\alpha$. This implies that $S_{1}$ must meet the condition opposite to (14) with $\alpha=\bar{\alpha}-h$. It is easy to show that given this constraint, the policy maker maximizes her utility in period 1 by setting $S_{1}=\frac{\lambda_{1} M_{0}^{2}}{(\bar{\alpha}-h) \lambda_{1} M_{0}^{2}+\lambda_{2}}$. 
2. Second separating equilibrium

(a) If some firms invest in period 1 when $\alpha=\bar{\alpha}+h$, and no firm invests in period 1 if $\alpha=\bar{\alpha}-h$, then $\beta_{1}$ is dependent on $\alpha$. Consequently, the policy maker adjusts her belief in period 2 to $\rho=1$ if $\beta_{1}=(\bar{\alpha}+$ h) $S_{1}$ and to $\rho=0$ if $\beta_{1}=0$.

(b) Suppose $\alpha=\bar{\alpha}+h$. The best response of firm $i$ to $S_{2}=S_{1}$ is to invest in period 1 if $c_{i} \leq S_{1}$ and never to invest in period 2. If all firms follow this strategy, no firm can be better off by deviating. Suppose now that $\alpha=\bar{\alpha}-h$. The best response of firm $i$ to $S_{2}>S_{1}$ is never to invest in period 1 and to invest in period 2 if $c_{i} \leq S_{2}$. If all firms follow this strategy, no firm can be better off by deviating.

(c) From lemma 3.3, we know that if $\alpha=\bar{\alpha}-h$, then given the strategy of the firms the policy maker sets $S_{2}=\frac{\lambda_{1} M_{0}^{2}}{\lambda_{1} M_{0}^{2}(\bar{\alpha}-h)+2 \lambda_{2}-1}$. In order for the strategy of firms to hold in equilibrium, $S_{2}=S_{1}$ must be true if $\alpha=\bar{\alpha}+h$ and $S_{2}>S_{1}$ must be true if $\alpha=\bar{\alpha}-h$. In other words, (i) $S_{1}$ must meet $S_{1} \geq \frac{\lambda_{1} M_{O}^{2}}{(\bar{\alpha}+h) \lambda_{1} M_{O}^{2}+\lambda_{2}}$ (an inequality opposite to (14) with $\alpha=\bar{\alpha}+h)$ and (ii) $S_{1}<\frac{\lambda_{1} M_{0}^{2}}{\lambda_{1} M_{0}^{2}(\bar{\alpha}-h)+2 \lambda_{2}-1}$ must hold. It is easy to show that if $h \leq \tilde{h}=\frac{\lambda_{2}-1}{2 \lambda_{1} M_{0}^{2}}$, then $\frac{\lambda_{1} M_{O}^{2}}{(\bar{\alpha}+h) \lambda_{1} M_{O}^{2}+\lambda_{2}}>\frac{\lambda_{1} M_{0}^{2}}{\lambda_{1} M_{0}^{2}(\bar{\alpha}-h)+2 \lambda_{2}-1}$ and (i) and (ii) never hold together. Thus, the equilibrium in question requires $h>h$. Suppose this is the case. Then, the expected utility of the policy maker equals:

$$
\begin{aligned}
& \frac{1}{2}\left[-\lambda_{1} M_{0}^{2}\left(1-(\bar{\alpha}+h) S_{1}\right)^{2}-\left(\lambda_{2}-\frac{1}{2}\right)(\bar{\alpha}+h) S_{1}^{2}\right] \\
& \quad+\frac{1}{2}\left[-\frac{1}{2} \lambda_{1} M_{0}^{2}-\frac{1}{2} \lambda_{1} M_{0}^{2}\left(1-(\bar{\alpha}-h) S_{2}\right)^{2}-\left(\lambda_{2}-\frac{1}{2}\right)(\bar{\alpha}-h) S_{2}^{2}\right]
\end{aligned}
$$

where $S_{2}=\frac{\lambda_{1} M_{0}^{2}}{\lambda_{1} M_{0}^{2}(\bar{\alpha}-h)+2 \lambda_{2}-1}$. It is straightforward to show that the above expression is maximized at:

$$
S_{1}^{*}=\frac{\lambda_{1} M_{0}^{2}}{\lambda_{1} M_{0}^{2}(\bar{\alpha}+h)+\lambda_{2}-\frac{1}{2}}
$$

It is obvious that $S_{1}^{*}$ meets condition (i) and it can easily be checked that $S_{1}^{*}$ meets condition (ii) iff $h>h^{\prime \prime}=\frac{2 \lambda_{2}-1}{4 \lambda_{1} M_{0}^{2}}>h^{\prime}$. 


\section{Proof of proposition 5.4}

\section{Proof.}

(i) Follows from the proof of proposition 5.3, 2c.

(ii) To prove this result it is sufficient to show that the second separating equilibrium (IIS) yields a higher payoff to the policy maker than the pooling equilibrium (P) both, when $\alpha=\bar{\alpha}-h$ and when $\alpha=\bar{\alpha}+h$. If this is the case, then the expected utility of the policy maker under IIS is larger than her expected utility under $\mathrm{P}$, and the former equilibrium always dominates the latter. Suppose that $\alpha=\bar{\alpha}-h$. Then it is easy to see that IIS yields a higher utility to the policy maker than P. While the period-1 utility is equal under both equilibria, the period-2 utility is higher under IIS since under this equilibrium the subsidy, optimal for the case $\alpha=\bar{\alpha}-h$, can be offered. Suppose now that $\alpha=\bar{\alpha}+h$. It is straightforward that IIS yields a higher utility to the policy maker than $\mathrm{P}$ since under IIS the subsidy, optimal for the case $\alpha=\bar{\alpha}+h$, is offered in period 1 .

(iii) Immediate.

(iv) Remember that we consider the case where $h>h^{\prime \prime}$. The expected utility of the policy maker under the second separating equilibrium, $E U^{I I S}$, can be obtained by substituting $S_{2}=\frac{\lambda_{1} M_{0}^{2}}{\lambda_{1} M_{0}^{2}(\bar{\alpha}-h)+2 \lambda_{2}-1}$ and $S_{1}$ as defined by (18) into (17). The expected utility in the static setting, $E U^{\text {stat }}$, is obtained by substituting (11) into (10). Calculating $E U^{I I S}-E U^{\text {stat }}$ yields:

$$
\frac{\left(\lambda_{1} M_{0}^{2}\right)^{2}(\bar{\alpha}-h) \Psi}{4\left(\lambda_{1} M_{0}^{2}(\bar{\alpha}-h)+2 \lambda_{2}-1\right)\left(2 \lambda_{1} M_{0}^{2}(\bar{\alpha}+h)+2 \lambda_{2}-1\right)\left(2 \lambda_{1} M_{0}^{2}\left(\bar{\alpha}^{2}+h^{2}\right)+\bar{\alpha}\left(2 \lambda_{2}-1\right)\right)}
$$

where

$$
\begin{aligned}
\Psi= & 4\left(\lambda_{1} M_{0}^{2}\right)^{2}\left(3 h^{2}-\bar{\alpha}^{2}\right)(h+\bar{\alpha})-\lambda_{1} M_{0}^{2}\left(2 \lambda_{2}-1\right)\left(6 h^{2}+8 \bar{\alpha}^{2}+10 h \bar{\alpha}\right) \\
& -3 \bar{\alpha}\left(2 \lambda_{2}-1\right)^{2}
\end{aligned}
$$

The sign of $\Psi$ determines the sign of the difference $E U^{I I S}-E U^{\text {stat }}$. It is easy to see that if $h \leq \frac{\sqrt{3}}{3} \bar{\alpha}, \Psi<0$ always. If $h>\frac{\sqrt{3}}{3} \bar{\alpha}$, then $\Psi>0$ is possible iff $\lambda_{1} M_{0}^{2}$ is large.

(v) This result holds since the second separating equilibrium improves on the static utility of the policy maker under uncertain $\alpha$ while any other equilibrium yields a lower utility than the static optimum under uncertain $\alpha$. 
Open Access This article is distributed under the terms of the Creative Commons Attribution Noncommercial License which permits any noncommercial use, distribution, and reproduction in any medium, provided the original author(s) and source are credited.

\section{REFERENCES}

Biglaiser, G., J.K. Horowitz and J. Quiggin (1995), 'Dynamic Pollution Regulation', Journal of Regulatory Economics, 8, pp. 33-44.

Brainard, W.C. (1967), 'Uncertainty and The Effectiveness of Policy', American Economic Review, 57, pp. 411-425.

Buchanan, J.M. (1969), 'External Diseconomies, Corrective Taxes, and Market Structure', American Economic Review, 59, pp. 174-177.

Buchanan, J.M. and G. Tullock (1975), 'Polluters' Profits and Political Response: Direct Controls versus Taxes', American Economic Review, 65, pp. 139-147.

Cadot, O. and B. Sinclair-Desgagné (1996), 'Innovation under the Threat of Stricter Environmental Standards,' in: C. Carraro, Y. Katsoulacos and A. Xepapadeas (eds.), Environmental Policy and Market Structure. Kluwer Academic Publishers, Dordrecht, pp. 131-141.

Cropper, M.L. and W.E. Oates (1992), 'Environmental Economics: A Survey', Journal of Economic Literature, 30, pp. 675-740.

Dijkstra, B.R. (1999), The Political Economy of Environmental Policy: A Public Choice Approach to Market Instruments. Edward Elgar, Cheltenham, UK.

Gersbach, H. and A. Glazer (1999), 'Markets and Regulatory Hold-Up Problems', Journal of Environmental Economics and Management, 37, pp. 151-164.

Glazer, A. and Ch. Lave (1996), 'Regulation by Prices and by Command', Journal of Regulatory Economics, 9, pp. 191-197.

Hahn, R.W. (1984), 'Market Power and Transferable Property Rights', Quarterly Journal of Economics, 99, pp. 753-765.

Hahn, R.W. (1990), 'The Political Economy of Environmental Regulation: Towards a Unifying Framework', Public Choice, 65, pp. 21-47.

Heyes, A. (2001). Honesty in a Regulatory Context - Good Thing or Bad? European Economic Review, 45, pp. 215-232.

Jaffe, A.B., R.G. Newell and R.N. Stavins, (2002), 'Environmental Policy and Technological Change', Environmental and Resource Economics, 22, pp. 41-69.

Laffont, J.-J. and J. Tirole (1993), A Theory of Incentives in Procurement and Regulation. The MIT Press, Cambridge, Massachusetts.

Malik, A.S. (1991), 'Permanent versus Interim Regulations: A Game-Theoretic Analysis', Journal of Environmental Economics and Management, 21, pp. 127-139.

Montero, J.P. (2002), 'Market Structure and Environmental Innovation', Journal of Applied Economics, 5, pp. 293-325.

Russell, C.S. and Ph.T. Powell (1999), 'Practical Considerations and Comparison of Instruments of Environmental Policy'. in: J.C.J.M. Van den Bergh (ed.), Handbook of environmental and resource economics. Elgar, Cheltenham, U.K. and Northampton, Mass., pp. 307-328.

Saracho, A.I. and J.M. Usategui (1994), 'Innovation Diffusion Subsidies: Supply without Precommitment Ability and Welfare', European Journal of Political Economy, 10, pp. 357-372. 
Sartzetakis, E.S. (1997), 'Tradeable Emission Permits Regulations in the Presence of Imperfectly Competitive Product Markets: Welfare Implications', Environmental and Resource Economics, 9, pp. 65-81.

Stavins, R.N. (1995), 'Transaction Costs and Tradeable Permits', Journal of Environmental Economics and Management, 29, pp. 133-148.

Weitzman, M.L. (1974), 'Prices vs. Quantities', Review of Economic Studies, 41, pp. 477-491.

Yao, D.A. (1988), 'Strategic Responses to Automobile Emissions Control: A Game-Theoretic Analysis', Journal of Environmental Economics and Management, 15, pp. 419-438. 